\title{
DISTURBANCES OF MICTURITION OBSERVED IN SOME PATIENTS WITH BRAIN TUMOR
}

\author{
Komei UEKI, M.D. \\ Dept. of Neurosurgery* \& Institute of Brain Research**, School \\ of Medicine, University of Niigata, Niigata
}

It is already a widely accepted concept based on numerous animal experiments $^{1-18}$ and clinical observations that above the level of the medulla oblongata, there exist some important centers partaking in regulating the micturition.

The following presentation is a systematic study on the relationship between the disturbed micturition and various intracranial tumors which were confirmed either by operative procedure or by autopsy. There added is a study of the disturbed micturition due to some surgical interventions to the brain. The materials are from 462 cases of operated intracranial tumors, 34 cases of frontal lobectomy and 16 cases of bilateral anterior cingulectomy. The last two are of non-neoplastic nature. All of the comatic and semicomatic cases were excluded.

In the brain tumor, the disturbed micturition presents itself in forms of dysuria (retardation, retardation combined with protraction), incontinence and pollakiuria. The dysuria is noticed in $58(12.6 \%)$ of all the patients of brain tumor examined. Incontinence and pollakiuria comprise $5.4 \%$ of all the patients surveyed; that is 25 among 462 . Thus the trouble of micturition is observed in 83 patients $(18.1 \%)$.

The analysis of the dysuria presents the following classification.

1. Those with retardation alone $(75.9 \%)$.

2. Coexistence of retardation and protraction $(6.9 \%)$.

3. Protraction which came up after a period of retardation and then both coexist $(3.4 \%)$.

4. An instance with a retarded micturition which later aggravated to retention $(5.2 \%)$.

5. Retention alone from the very beginning $(3.4 \%)$.

6. Coexistence of retardation and protraction mixed with occasional incontinence $(5.2 \%)$.

As to the location of the lesion, the primary tumor from the pons gave the highest incidence of dysuria: namely 17 cases $(77.3 \%)$ of all the tumors coming out of this area. The tumor of the 4th ventricle came next with 6 cases $(66.7 \%)$.

\footnotetext{
*Director: Prof. K. UeKI.

** Director: Prof. K. UEKI.
} 
The third is the one in the midline of the cerebellum with the incidence of 9 cases $(40.9 \%)$. There were followed by the tumor from the cerebellar hemisphere, with dysuria occuring in 8 cases $(24.2 \%)$, and the tumor from the cerebellopontine angle with 6 cases $(9.1 \%)$. We have also noticed 2 cases of dysuria associated with a tumor arising from the pineal body, 2 cases in tumor from the subcortical deep portion of the cerebrum, and 6 cases in a tumor of the hemisphere, however, in view of the relatively high incidence of tumors arising in these three areas, the percentage of the dysuria related to the tumor is extremely low (Table 1).

In the patients with so called incontinence, we saw 21 cases of pure incontinence and 4 of pollakiuria. From the topographical point, tumor in the hemisphere of the cerebrum gave 12 cases of incontinence, which constitutes $7.2 \%$ of all the cases with tumor from this area examined. The tumor of the cerebral

Table 1.

\begin{tabular}{lrcc}
\hline Location of tumors & No. of cases & $\begin{array}{c}\text { No. and per cent of cases } \\
\text { complained dysuria }\end{array}$ \\
\hline Pons & 22 & No. & per cent \\
4th ventricle & 9 & 17 & 77.3 \\
Midline of cerebellum & 22 & 6 & 66.7 \\
Cerebellar hemisphere & 33 & 9 & 40.9 \\
Cerebellopontine angle & 66 & 8 & 24.2 \\
Pineal body & 27 & 6 & 9.1 \\
Optic chiasm region & 80 & 2 & 7.4 \\
Midline of the cerebrum & & 2 & 2.5 \\
3rd ventricle & 34 & & 5.9 \\
Lateral ventricle & 167 & 2 & 3.6 \\
Cerebral hemisphere & 2 & 6 & 12.6 \\
Multiple & 462 & 0 & 5 \\
\hline
\end{tabular}

Table 2.

\begin{tabular}{lccc} 
Location of tumors & No. of cases & \multicolumn{2}{c}{$\begin{array}{c}\text { No. and per cent of cases } \\
\text { complained incontinence }\end{array}$} \\
\hline $\begin{array}{l}\text { Cerebral hemisphere } \\
\text { Midline of the Cerebrum } \\
\text { 3rd ventricle } \\
\text { Lateral ventricle }\end{array}$ & 167 & 12 & per cent \\
$\begin{array}{l}\text { Subtentorium } \\
\text { Multiple }\end{array}$ & 141 & 10 & 7.2 \\
Total & 152 & 3 & 7.1 \\
& 2 & 0 & 1.9 \\
\hline
\end{tabular}


hemisphere is followed by the one from the cerebral subcortical deep portion which presents 10 cases $(7.1 \%)$. These two are almost identical in the incidence of the incontinence. Of 152 cases of tumor from the posterior cranial fossa, only three $(1.9 \%)$ showed incontinence (Table 2). Examination of the tumors of the cerebral hemisphere revealed that those tumors with the symptom are almost all confined in the frontal lobe; namely 10 among 76 cases $(13.2 \%)$. In the parietal lobe, the ratio is 2 among 32 cases $(6.3 \%)$. In this series, tumors from the occipital and the temporal lobe are free of incontinence (Table 3 ).

Table 3.

\begin{tabular}{lccc}
$\begin{array}{l}\text { Location of tumors } \\
\text { Cerebral hemsiphere }\end{array}$ & No. of cases & $\begin{array}{c}\text { No. and per cent of cases } \\
\text { complained incontinence } \\
\text { po. }\end{array}$ & $\begin{array}{c}\text { per cent } \\
\text { Frontal }\end{array}$ \\
Central & 76 & 10 & 13.2 \\
Parietal & 14 & 0 & 0 \\
Occipital & 32 & 2 & 6.3 \\
Temporal & 10 & 0 & 0 \\
Total & 35 & 0 & 0 \\
\hline
\end{tabular}

We can summarize the above as follows;

1. In brain lesions dysuria comes more often than incontinence.

2. Most of the tumors associated with dysuria are subtentorial tumors while almost all of tumors with incontinence are supratentorial tumors.

3. Dysuria is noticed with high incidence in tumors in the area of the pons and the medulla oblongata, and the tumors that have a close contact with this area have the next highest incidence of dysuria.

4. Incontinence has preference to occur in the tumors anterior to the motor area of the cerebrum.

Further examination of the subtentorial tumors showed that tumor with dysuria occurs in the brain stem concentring and around the pons, in the 4th ventricle, in the midline of the cerebellum, in the cerebellar hemisphere, in the cerebellopontine angle more often in the order described (Table 4).

Table 4.

Location of tumors
Subtentorial
Pons
4th ventricle
Midline of the cerebellum
Cerebellar hemisphere
Cerebellopontine angle
Pineal body

No. of cases

No. and per cent of cases complained dysuria

No. per cent

$\begin{array}{lll}66 & 6 & 9.1 \\ 27 & 2 & 7.4\end{array}$


Usually, tumors of the pons found at autopsy were invading the midbrain and the medulla oblongata and we found out that 16 among 19 cases of glioma $(84.2 \%)$, appearantly arising primarily from the pons were associated with dysuria. Of the primary glioma from the midbrain, two of the three cases which were localized in the tegmentum of the midbrain were not associated with dysuria. Only last one with an extensive infiltration to the pons and the upper structure beyond the midbrain, confirmed at autopsy, had a symptom of dysuria. Thus it is possible to conclude that dysuria does not appear until the tumor invades the pons or the upper part of the medulla oblongata. There found were 9 cases of neoplasm occupying the 4th ventricle, and 6 of them had dysuria (66.7\%). The 4 of the six were ependymoma, and the rest were astrocytoma and sarcomatous meningioma, and all of these appearantly have a might influence to the pons and its vicinity of the brain stem. On the contrary, a case of ependymoma which has extended to the pontine angle and a case of papilloma of the choroid plexus were free of dysuria. There were 22 tumors in all which sprang up from the midline of the cerebellum. Nine of them had complaint of dysuria $(40.9 \%)$. All of these nine cases showed a marked infiltration to the 4th ventricle with a complete occupation of it. Histologically these are almost all medullablastoma. Eight of the thirty-three $(24.2 \%)$ tumors arising from the hemisphere of the cerebellum had the same symptom. Judging from the fact above-mentioned, it seems to be possible to state that there exists no such important center in the cerebellum itself as regulates the micturition. Among the 66 cases of tumors of the cerebellopontine angle, only $6(9.1 \%)$ had complaint of dysuria. Therefore it is justified to conclude that there is no important center on the ventral side of the medulla or of the pons.

The dysuria occurs quite irregularly. The earliest dysuria comes at the same time when the other primary symptoms appear, while in some patients it delays to occur until right before the patient expires. In majority of cases its duration ranges from a month to 6 months. But this does not necessarily mean that it stays for the entire period but there are, usually some intermessions with free urination.

Then, how does an operation or radiation therapy affect the course of dysuria? In a series of glioma of the pons and its vicinity in the brain stem which were treated mostly by $\mathrm{Co}^{\mathrm{fi}}$ or $\mathrm{x}$-ray radiation, we could follow 10 cases well and 5 cases of dysuria showed a marked improvement. In an usual case, amelioration of the general neurological symptom is always accompanied by an improvement of dysuria. Therefore, there must be an important center for micturition in this area. The author observed 6 cases of tumor occupying the 4th ventricle. Three of 4 cases of ependymoma had a suboccipital decompression and partial resection of tumor and we saw a marked amelioration of the dysuria but sarcomatous meningioma did not show any significant change with the same procedure, finally in a case of astrocytoma, an extensive infiltration into the cerebellum 
was noticed, the patient expired after the operation. Five cases of medulloblastoma arising from the midline of the cerebellum had craniectomy for decompression or Tolkildsen's procedure followed by radiation therapy and three of them had an improvement, with 4th one without significant change and the last out of our follow-up. It is worth-while to notice that all of the cases of tumors arising from the cerebellar hemisphere upon which decompression, with partial or complete resection of tumors had been done showed a marked improvement of the dysuria. Post operative observations about 4 cases of tumors of the cerebellopontine angle showed that 3 had an improvement. In all of these three cases, we saw a lowered pressure postoperatively as if we had a total resection of the tumor. Of the pineal body tumors, two cases that reacted well to the radiation therapy by $\mathrm{Co}^{60}$ had no trouble of micturition. In view of the improvement of the dysuria after the operation or radiation, especially of the improvement in a case when the pressure to certain brain stem area is considered to have been removed, it is of the highest possibility that there exists a vital center of controlling the micturition in this area.

Topography of the supratentorial tumors associated with dysuria showed two cases in the optic chiasm region, two in the extremely deep portion, and one or two in various parts of the cerebral hemisphere. Judging from the incidence, the locality of the tumors has no significance for the dysuria and the incidence itself is quite small.

It is quite clear that the locality of tumors on the hemisphere does not contribute anything to the dysuria; for there is always a certain improvement of dysuria after an extirpation of the tumor or a lobectomy.

Incontinence in a case of subtentorial tumor is almost negligible because of the low incidence, but the supratentorial tumor gives a significant rate of occurence (7\%).

Among the tumors of the cerebral hemisphere associated with incontinence, 10 out of 12 are those from the frontal lobe and the remaining two are parietal tumor. Of the frontal tumor, incontinence has a high incidence in rather subcortical tumor or medial surface tumor than the tumors of other site or form. Then, does the frontal lobe have anything to do with incontinence?

Using the statistics of frontal lobectomy, Itai $^{26}$ in our department made a survey on this point under the direction of Dr. Nakata and concluded that 7 out of $43(16.3 \%)$ cases of frontal lobectomy had a transient incontinence lasting for a week to a month. Two out of 43 cases of the right frontal lobectomy had a transient incontinence, while three out of 5 cases $(60 \%)$ of left frontal lobectomy and two of 4 cases of bilateral frontal lobectomy showed an incontinence temporalily (Table 5). In the frontal tumor, incontinence comes out in $13.6 \%$ of them, and the difference of the incidence between the right and left lobe is minimum. The facts above-mentioned suggests that a lesion of the right frontal lobe does not have a direct relationship with the incontinence and the disturbed 
Table 5 .

\begin{tabular}{cccc} 
Operative procedure & No. of cases & \multicolumn{2}{c}{$\begin{array}{c}\text { No. and per cent of cases } \\
\text { complained incontinence }\end{array}$} \\
\hline Right frontal lobectomy & 34 & No. & per cent \\
Left frontal lobectomy & 5 & 2 & 5.0 \\
Bilateral frontal lobectomy & 4 & 3 & 60.0 \\
Total & 43 & 7 & 50.0 \\
\hline
\end{tabular}

left frontal lobe has something to do with the incontinence. When a tumor invades deeper into the subcortical substance of the frontal lobe or if a tumor infiltrates the medial surface of the both frontal lobes, the incidence of the incontinence rises higher. Usually incontinence after frontal lobectomy is transient. Therefore it is difficult to attribute the incontinence to the abscence of the frontal function.

Of twenty cases of tumor invading the paracentral lobule, three (15\%) were associated with incontinence. When the paracentral lobule is invaded on one side alone, it seems to be free of incontinence until the both sides are invaded.

Among the 16 cases of the bilateral frontal cingulectomy, only one case showed a symptom once a desire to urinate felt, it always demanded an immediate micturition without delay. Two other cases with incontinence were noticed in the above series, however, these two patients were in such poor state that they lacked completely the mental initiatives. Thus, it is quite unlikely that this is rather signicant in controlling the micturition.

Tumor that replaced the subcortical deep portion of the cerebrum gave incontinence with a rate of $7.1 \%$ but we were not successful in giving a clearcut topographical classification because of its complexity.

Our present study strongly supports those results of experiments by Barrington, ${ }^{3-8)}$ Kuru, ${ }^{18)}$ Langworthy, ${ }^{9-10)}$ Tang ${ }^{13,14)}$ and etc. These studies strongly suggest that there are important centers partaking in contracting the bladder thus keeping a smooth micturition somewhere between the pons and the medulla oblongata, and also close to the lower part of the midbrain. It is clear that these are not nerve tracts, for the complete occupation of the upper midbrain by an invading tumor does not give any symptom characterized by dysuria.

Langworthy ${ }^{9,10)}$ theorized them as being reflex-centers for regulating the tonus of the bladder. Tang ${ }^{13,14)}$ regards them as centers to promote the micturition threshold, while Kuru ${ }^{18)}$ found out two groups; one for contracting and other for dilating the bladder. We made a survey on the status of the tonus of the bladder and the micturition threshold under the various lesions of the brain through cystometrography. Both supratentorial and subtentorial tumors gave no significant findings either in the bladder-tonus or in the micturition threshold to cysto- 
metrography as a general view. This may be reasonable, because almost these patients had no complaint of marked dysuria all through their clinical course. There are, however, a few cases of frontal tumor with a complaint of incontinence, whose cystometrography showed a marked increase of the internal pressure of the bladder along with an inversely lowered micturition-threshold (Fig. 1). It is also with an interest to notice that in case of a tumor of the posterior cranial fossa, the internal pressure of the bladder is decreased and the micturition-threshold is extremely enhanced, and the duration between the point of pain due to overdistention and the point of micturition is fairly prolonged (Fig. 2).

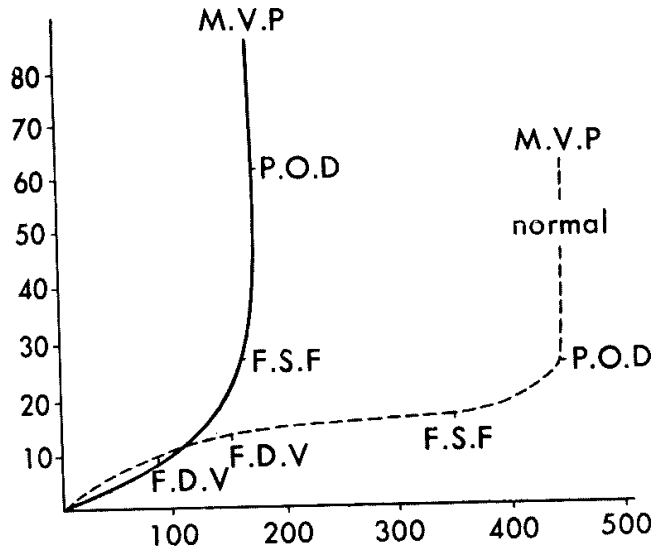

F. D. V-First Desire of Void

F.S. F - First Sensation of Fullness

P. O. D-Pain of Overdistension

M. V.P-Maximum Voidpressure

Fig. 1. Cystometrogram of one frontal tumor.



F.D.V-First Desire of Void

F.S.F.-First Sensation of Fullness

P.O.D -Pain of Overdistension

M.V.P-Maximum Voidpressure

Fig. 2. Cystometrogram of one acoustic neurinoma.

\section{Summary}

Through the clinical study of brain tumors, we had a conclusion on the cerebral mechanism which influence the sacral center on the micturition. That will be described as follows:

1. The frontal lobe has something to do with inhibitory function of the micturition especially the left frontal lobe seems to be very significant. 
2. It is very doubtful that there is an inhibitory factor in motor area.

3. The paracental lobule seems to have an inhibitory function, incontinence, however, may not appear unless both lobules are invaded.

4. The possibility of the existence of an inhibitory center in the cingulate gyrus is extremely doubtful. It is out of our consideration that there exists, at least, an inhibitory center on the anterior cingulate gyrus.

5. It is also doubtful that there is an inhibitory or an accelerating center in the diencephalon.

6. The upper part of the mesencephalon appears to be no important center of micturition.

7. It is clear that there are some accelerating center of micturition in the area of lower mesencephalon and upper medulla with the pons as its significant site (Fig. 3).

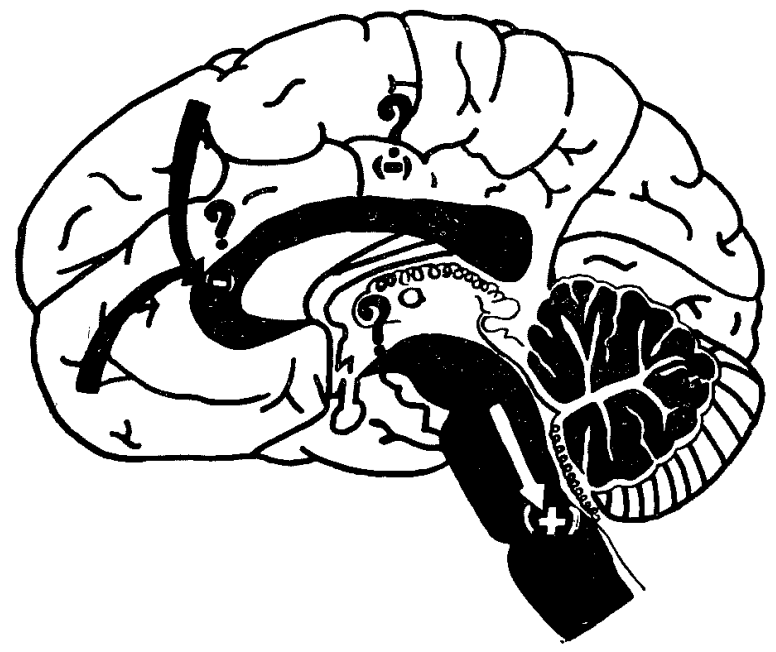

Fig. 3. Schematic representation of cerebral control of micturition.

\section{References}

1) Karplus, J. P. u. A. Kreidl: Gehirn und Sympathicus. I. Zwischenhirnbasis und Halssympathicus. Pfiug. Arch. ges. Physiol., 129: 138, 1909.

2) Lichtenstern, R.: Ueber die zentrale Blaseninnervation, ein Beitrag zur Physiologie des zwishenhirns. Wien. Klin. Wschr., 25: 1248, 1912.

3) Barrington, F. J. F.: The nervous mechanism of micturition. Quart. J. exp. physiol, $8: 33,1914$.

4) Barrington, F. J. F.: The relation of the hindbrain to micturition. Brain, 44:23, 1921.

5) Barrington, F. J. F.: The effect of lesions of the hind and midbrain on micturition in the cat. Quart. J. exp. physiol., 15: 81, 1925. 
6) Barrington, F. J. F.: The central nervous control of micturition. Brain, 51: 209, 1928.

7) Barrington, F. J. F.: The component reflexes of micturition in the cat. Parts I and II. Brain, 54: 177, 1931.

8) Barrington, F. J. F.: The component reflexes of micturition in the cat. Part III. Brain, 64: 239, 1941 .

9) Langworthy, O.R. and Kolb, L. C.: The encephalic control of the tone in the musculature of the urinary bladder. Brain, $56: 371,1933$.

10) Langworthy, O. R., Kolb, L. C. and Lewis, L. G.: Physiology of micturition. Baltimore, Williams \& Wilkins, 1940.

11) Beattie, J. and A. S. Kerr: The effects of diencephalic stimulation on urinary bladder tonus. Brain, 59: 302, 1936.

12) Magoun, H. W., S. W. Ranson and A. Hetherington: Descending connections from the hypothalamus. Arch. Neurol. Psychiat., 36: 1128, 1938.

13) Tang, P. C.: Brain stem control of micturition and respiration. A thesis submitted in partial fulfillment of the requirements for the degree of Doctor of Philosophy. Univ. Washington, 1953.

14) Tang, P. C.: Lebels of brainstem and diencephalon controlling micturition reflex. J. Neurophysiol., 18: 583, 1955.

15) Tokunaga, S.: Contraction and Relaxation of urinary bladder following electrical stimulation of the medulla. J. J. S. S., 57: 1603, 1956. (Japanese)

16) Akagi: Experimental study on descending tract from the center of urinary bladder in the medulla. Med. J. Osaka Univ., 10:45, 1958. (Japanese)

17) Kurachi: Experimental study on descending tract from the center of contraction and relaxation of urinary bladder in the medulla. Med. J. Osaka Univ., 9: 69, 1957. (Japanese)

18) Kuru, M. and H. Ozaki: Evidence presented for the existence of the micturition center in the medulla. Proc. Japan Acad., 35: 186, 1959.

19) Czyhlarz, E. und O. Marburg: Ueber cerebrale Blasenstörung. Jahrb. f. Psychiat. u. Neurol., 20: 134, 1901.

20) Friedmann, M.: Zur Kenntnis der zerebralen Blasenstörung. Münch. med. Wschr., 50: $1951,1903$.

21) Adler, A.: Ueber organisch- (kortikale) und funktionellnervöse Blasenstörungen. Dtsch. Z. Nervenh., 65: 72, 1920

22) Watts, J. W. and C. A. W. Uhle: Bladder dysfunction in case of brain tumor. A cystometric study. J. Urol., 34: 10, 1925.

23) Holman, E.: Difficult urination associated with intracranial tumors of the posserior fossa. Arch. Neurol. Psychiat, 15: 371, 1926.

24) Whitty, C. W. M.: Effects of Anterior Cingulectomy in Man. Proc. Roy. Soc. Med., 48: 463, 1955.

25) K. Yamaguchi: Distriturbances of micturition in patients with braih tumor. Psychiat. Neurol. Jap., 61: 239, 1959. (Japanese)

26) Itai, S.: Beobachtungen über die frontallobektomierten Patienten. Psychiat. Neurol. Jap., 46: 225, 1942. (Japanese) 